\title{
ANTHROPOLOGY AND BUSINESS MANAGEMENT-TOOL TO ATTAIN COMPETITIVE ADVANTAGE
}

\author{
SIGAMANI PANNEER \\ CENTRAL UniVERSITY OF TAMIL NADU, THIRUVARUR \\ N U KHAN \\ Jamia Millia Islamia (A Central University), NeW Delhi \\ SHWETA MALHOTRA \\ Jamia Millia Islamia (A Central University), NeW Delhi
}

The recent past has witnessed a trajectory in terms of growth of anthropology as a discipline along with its application in various fields. One of the most talked about fields of applied anthropology is anthropology in business or business anthropology. The world has recognised that business is not just an economic activity but an activity which has a human angle hence neo-classical principles have replaced the classical thought. More and more organizations are embracing research to understand the people side of business. For this, anthropologists are being hired to investigate vital processes such as organization policies, design, culture, leadership, consumer behavior, and so on. The present article discusses the concept and meaning of this newly-arrived discipline of anthropology, followed by its contribution to business in the present century. Further, it also elaborates the relevance of business anthropology, the practical issues faced in its implementation, and its emerging fields.

Keywords: business anthropology, culture, research methods, observations, ethnography, management 


\section{Introduction}

Business anthropology refers to the implementation of ideas and techniques from the field of applied anthropology to attain the objectives of primarily those businesses that are run for profit and attain competitive advantage. The present business world is not just characterized by profitability but also sustainability. Anthropological principles not only help businesses achieve higher profits but also sustain them in the long run. Business anthropology is further defined as a practically-oriented scholastic field in which anthropological theories and methods are applied to identify and solve real business problems. In other words, the foremost objective of anthropology is to resolve operational and organizational glitches. The term became popular in the late nineteenth century, when it was applied to areas such as consumer behavior and marketing. The past three decades have witnessed a spurt in the growth of the field and its application to a plethora of contexts in business. Hence, the term "business anthropology" is used generically to refer to any application of anthropology to business management. Changes in the global business, such as technological advances and integration, have not only altered the way business is steered but also modified the way people perceive business and business activities. All these have led to tremendous competition, hence business leaders today need to re-examine the various offerings, such as products and services, how they are offered, who are the new collaborators to deliver new products and services, and so on. To cater to the multifaceted, ever-changing customer requirements and to attract new customer groups, there is a dire need to diversify the product line and that, too, at a fast pace. Many companies, such as Proctor and Gamble and Hindustan Unilever, have increased their product offerings by diversifying in varied product categories and anticipating future customer demand.

More specifically, business anthropology entails helping organizations manage demographic disparities like cultural and ethnic uniqueness. In some cases, business anthropologists act as an interface between the management and the workforce (Reice, 1993). Anthropology as a discipline can also contribute towards promoting best practices which are ethical and are framed keeping in mind the interest of the consumer and society at large.

The significance of anthropology has increased manifold as it is being used in varied fields, such as business consulting, organizational behavior, human resources management, competitive intelligence, globalization, product design and development, marketing, and consumer behavior studies (Baba, 2006; Jordan, 2010; Tian, Van Marrewjik and Lillis, 2013). Jordan (2010) proposed that business anthropology is of three types, namely: 1) 
organizational anthropology (the analysis of multifaceted organizations including their cultures, work processes, and change directives); 2) anthropology of marketing and consumer behavior; and 3) design anthropology (product and services design). There have been two other fields added recently, namely anthropology of competitive intelligence and knowledge management and international and cross-cultural business (Tian and Lillis, 2009; Ferraro, 1998). Although business anthropology is like any other applied field of anthropology, there is a fundamental difference based on the methods used. Gwynne (2003) advocated that the distinction between business anthropology and the other subfields is based on the techniques and procedures used. This is because the investigations made by the business anthropologists basically revolve around attempts to help organizations derive profits. All this leads to openness of results, publishing of actual findings, and ethical considerations. There are innumerable contributions that anthropology can make to business and its role in the present century is even more noteworthy.

\section{Business Anthropology in the $21^{\text {st }}$ Century}

The functions and roles of business anthropology are highly extensive and have expanded with time. Anthropological interventions are not only into traditional, macro-management functions such as marketing, human resource, operations, etc., but also into specialized or micro-functions such as advertising, consumer behavior, sales promotion, product design, and so on. Business anthropologists study all the business arenas such as marketing, operations, organizational culture, human resource management, international business, and so on (Tian, Van Marrewjik and Lillis, 2013). At some places, it solves multifarious business problems such as acceptance of new technical tools, methods, and processes by reluctant workers, creating an organizational culture incorporating people from distinctive ethnic, educational, religious, and cultural backgrounds (Schwartz, 1991). In other instances, it contributes to the business in an inimitable way (Jordan, 2010). The primary role of the business anthropologists is thus to investigate the causes of these real-life problems and suggest feasible solutions for the same. The primary distinction between business anthropology and the other sub-fields of anthropology is that business anthropology looks at organizations not only as economic entities but also congregations of people similar in certain aspects. The area of concern for the business anthropologists is the formal face of corporate culture along with the informal one (Garza, 1991). In other 
words, they look at not just what meets the naked eye, but also at what goes on behind the scenes.

The methods used for research in business anthropology incorporate qualitative and ethnographic methods to inspect organizational phenomena, unlike the more formal methodologies. Other tools which are specific to anthropology in organizations include participant observation, informal and structured interviews, and other "realistic", informal, and face-to-face methods of inquiry. The contribution of anthropologists is immense, but more specifically, the business anthropologists help the corporations by developing methods of doing business which are culture appropriate.

The business arena is an amalgamation of various real life-problems and the anthropologists examine the human side of business. Hence, they attempt to answer questions connected to human resources, such as: Why do people do what they do? What is their intent while doing so? Some other generic issues which business anthropologists look at are: Who are the leaders and who are the followers in the business? How many diverse clusters of people exist in the business? What are the commonalities in terms of value systems, beliefs, and attitudes inside the business? How does the political hierarchy work? How do the dynamics of authority and responsibility work? How is information disseminated among the group members? What is the flow of information and communication among the members of the group? What are the reasons for clashes among group members and among groups, and how are these fixed?

Business anthropology thus helps the organizations evolve culturally sensitive policies and strategies in a business realm which is characterized by cross-cultural contacts (Jordan, 2003; Ybema et al., 2009). Aguilera (1996) says that although the field is expanding rapidly, there is still a high degree of resistance in embracing the anthropological theories as it is difficult to comprehend the direct effect and implication of the anthropological investigations on the business function.

\section{Significance of Business Anthropology in Contemporary Business}

Business anthropology has been used increasingly in different industries to investigate a wide variety of real-time business problems. For example, anthropology has been used in the consumer goods industry where technological advancement has stimulated rapid growth. The changing business scenario puts across many challenges, such as integrating the fragmented consumer markets to fit them to the emerging business models. 
This in turn requires novelty in the existing products and services to satisfy the ever-changing customer requirements. The scenario requires increased interaction between the producers and the end consumer-anthropologists have a major role to play in such situations (Tian, 2005; Tian and Walle, 2009).

Another example of the application of business anthropology is a quantitative survey that was conducted by Robert Tian, Dan Trotter, and Linlin Zhang (2014) through anthropological techniques (such as participant observation and in-depth interviews) to investigate the quality of food service operations at a Chinese university. According to the researchers, the utility of anthropological investigation in such a case is because the quality of food service has a great impact on the satisfaction level of the students, who are the customers. Hence, they recommended the inclusion of this parameter in the overall evaluation of the universities to in turn enhance the quality of food services rendered. The anthropological intervention therefore helped gauge the importance of consumer behavior and what factors affect the level of consumer satisfaction.

Business giants such as Google and Proctor and Gamble have realized the importance of anthropology to promote their products and services in new markets and capture new customers. Google uses the ethnographic method to cognize the needs of the consumers, which includes capturing video of people searching on the web. An example of this in the Chinese context is of people of China who were having a tough time searching and getting optimum results owing to the language barrier. This led Google to make "Google Suggest", which would initiate pop-up search suggestions so that users could take a cue while typing. The "Did You Mean?" service is an example of this. As a result of their offerings, they got appreciation from their users. These innovations were a result of Google's consumer observation, understanding, and insight gathering methods, which are nothing but anthropological techniques.

Proctor and Gamble used similar techniques to counter many product failures in the 1980s. The detergent it launched for the lower income group was a failure. So it started the "Living It" program, also known as "Immersion Research", to understand the aspirations, desires, and needs of the particular customer segment. This led to gathering of the consumer or partner insight into the not-so-evident but crucial needs of consumers. The executives realized that customers, who mainly comprised manual labor, were very sensitive to perspiration odors, and obtained satisfaction in cleaning their clothes by seeing their detergent foam - the feature which the new detergents lacked. Hence, customer observation through live-in 
immersion or video observation is a vital tool used by organizations these days.

Julian Orr (1995) applied anthropology in a business setting when he tried to understand culturally constructed meanings and their associations with work practices among the repair technicians at Xerox. The researcher wanted to study how they were able to repair models of copiers without having the formal training or expertise to do so. He was exposed to the fact that the technicians circulated technical repair information by trading work "war stories". They resolved tricky issues by connecting the stories they had learnt of their colleagues' procedures to progress in their own circumstances. The researcher suggested to the company it capitalize the source of knowledge and the company equipped all the technicians with radio-phones to make communication between them easier. Orr also found out that customers were the source of knowledge about the working of the machines, and the technicians were the source of knowledge on customers, in addition to their core area. Hence, the employee was a knowledge worker.

Bennett (1996) rightly points out that applied forms of anthropology, in this case business anthropology, "translate cultural relativism into conservation of local ways and adaptations to make sure that change is not overly punishing or that any induced change has a beneficial effect". Although business anthropology has an application in a plethora of areas of business, there are still many practical issues to be resolved, which one encounters only when actual research is conducted. The following section details the contingencies faced by the anthropologists while implementing the anthropological principles to business problems.

\section{Emerging Issues in Business Anthropology Research}

Since anthropology aims to solve human issues, there are many areas of concern during actual implementation when using anthropological methodology and tools of research and data retrieval. The anthropologists also work as professional consultants to solve actual world glitches and matters. This incorporates the application of the study of human culture, behavior, language, and biology. The basic tools used for any business anthropology research are observation, ethnography, in-depth interviews, and so on. These aid the organizations or businesses in understanding the "other", which could be an individual or a group of people different from the observer. Further, they help to accrue comparisons, differences, and evolutionary facts to gain an all-inclusive outlook on a diverse way of human life. 
One of the most important practical issues faced in any kind of business anthropology research is related to the depth of involvement of the anthropologists in the issue. Anthropological data is susceptible to contagion by probable integration of the social scientists into the culture they are studying, which might dilute the actual data collected from the field. Another potential issue a business anthropologist is likely to face is that the focus of the research often revolves around the desired outcome, which can make the data undependable. This happens because of client pressure to prove the effect of a product or service on a group of people. To ensure the validity of data, the anthropologist should learn the art of harmonizing the interests of the client and the group under study, which may be conflicting at times. A very evident example of such a situation of conflicting interests of the client and the group needs was Japanese internment camps (in the US) during World War II. Here the anthropologists' research was not conducted very scientifically and was done more for the government's security demands. This resulted in many Japanese Americans losing their homes, propriety, and dignity through the applied anthropologists' advice on how best to help the country protect itself from Japanese spies during the war. The government and American society's stigmatizing of the enemy caused a lack of cultural understanding to be applied that might have otherwise helped all the parties involved and prevented the establishment of the Japanese internment. Such acts reflected poorly on the field and on the credibility of the reports (Embree, 1945).

Yet another practical issue concerning the field arises because of lack of a theoretical foundation of its own as a discipline. This poses a threat to the field as an academic discipline. This issue has also led to less attention being given to business anthropology. Ethics is one of the issues which business anthropology struggles to address. The client-subject interaction and responsibility often place a business anthropologist in an ethical dilemma. This ethical contradiction is left to the anthropologist to sort out. As a consequence, the business anthropologists avoid taking up any kind of assignment which places them in situations of ethical quandary. The responsibility of the employer of an anthropologist is to provide considerable independence, allowing the anthropologist to criticize a boss or the company and to defend study groups against negative consequences (Bennett 1996). 


\section{Recommendations}

The field of anthropology has been expanding at a great pace, and more and more organizations have started accepting anthropological principles as possible remedies for many of their hurdles. But at the same time, it is important to take into consideration certain aspects which accompany any kind of implementation of anthropological concepts to real business issues. While anthropology is applicable to many issues and contexts, it cannot provide a solution to the entire range of business problems. Hence, researchers and implementers need to gauge the relevance of an anthropological principle to the business context and then expend it. If applied otherwise, the results derived could be misleading and distorted. Moreover, it is important to customise according to the requirements of the customers or clients (Sigamani and Malhotra, 2013). If the organization fails to customize the methodology to suit the requirement of the consumer, the intervention could be a complete waste.

Secondly, since this is an evolving field of study and operation, the best practices need to be documented so that they can be used in similar business situations. This would help in conserving a lot of time which goes into undertaking full-fledged research. Thirdly, the role of anthropology in business has multiplied much faster than estimated. These developments need to be considered in business management courses. Gremler et. al., 2000, say that business management courses are generally designed to be quantitative in nature, with qualitative methods accorded much less importance. But, currently, anthropological methods such as participated observation, ethnography, etc., have been applied to many sub-disciplines of management, such as consumer behavior, marketing, human resource management studies, advertisement management, and so on.

More research should be conducted in the area so that it benefits the businesses and community as a whole. The major benefit of anthropology is that it answers the questions about consumers and consumption behaviour to make products and services more suitable. Further, it also helps gain understanding of the social groups in the society, and the employee behavior, perception, attitude, and values in organizations. This helps to enhance the quality of life in society and the performance and efficiency in organizations. Finally, academia and practitioners need to integrate their efforts in this direction to accrue the benefits of anthropological research and findings and help benefit all the players of the global society. 


\section{Summary and Conclusion}

The increasing complexity of the global economy has led to the unification of diverse cultures of the world, and the business practices which were locale specific are global in nature today. This has given rise to an incessant need to understand people better in the context of business. Anthropology studies society as a unit of individuals and as groups of individuals, and answers questions of societal concern often left unanswered by other disciplines. Business anthropology appears to be one tool which has come to the rescue of the organizations to help them come to terms with human beings and their intricacies. Applying anthropological principles to business is bound to help organizations achieve sustained competence and efficacy. Application of anthropological principles to real life contexts, in this case business, may not have been completely recognized by academia, but applying them would definitely lead them to more chances of success. The present article looks at the issues involved in the anthropological research in the business arena. It discusses the contribution of anthropology to the different areas of management and illustrates how it helps in solving the different issues of business.

Business anthropology has been expanding, and research is being conducted in numerous countries with several organizations. It can be used for different business needs and can contribute a lot to the real business scenario. Anthropologists have been working outside academia in organizations, consulting firms, design studios, and marketing agencies. Some of the areas that business anthropologists have forged into are corporate cultures, knowledge management, cultural audit, organizational change, product design and development, marketing, consumer behavior, and international business studies, and these are ever-increasing. Business anthropologists can also offer their support to areas such as competitive intelligence, international business, human resources management, and operations. Many countries such as China, Japan, Australia, Central America, and those in Europe are sponsoring anthropologists to work on issues in the organizations, in the designs, and in consumer behaviors. Business anthropology is a global field and associations with researchers around the world can fortify this area of research and practice. There has been rising international interest in business anthropology through research, student training, and consulting. To summarise, business anthropologists have the potential to make instrumental contributions to the existing business world, and it would be realistic to anticipate business anthropology as one of the most demanded disciplines in the world in the near future. 
10 Anthropology and Business Management-Tool to Attain Competitive Advantage

\section{References}

Aguilera, F.(1996). 'Is Anthropology Good for the Company?' American Anthropologist, 98(4): 735-742.

Bennett, John W. (1996). 'Applied and Action Anthropology: Ideological and Conceptual Aspects.' Current Anthropology. Supplement: Special Issue: Anthropology in Public, 37(1): S23-S53.

Baba, M. (2006). 'Anthropology and Business.' In H. James Birx (Ed.) Encyclopedia of Anthropology (pp. 83-117). Thousand Oaks, CA: Sage Publications.

Embree, John F.(1945). 'Applied Anthropology and Its relationship to Anthropology.' American Anthropologist, 47(4):635-637.

Ferraro, G.(1998). Cultural Dimension of International Business $\left(3^{\text {rd }} \mathrm{ed}.\right)$, Upper Saddle River, NJ: Prentice Hall.

Garza, C. (1991). 'Studying the Natives on the Shop Floor.' Accessed August 28, 2016. http://www.bloomberg.Com/news/articles/1991-09-29/ studying-on-the-shop-floor.

Gremler, Dwayne D., K. Hoffman Douglas, Susan M. Keaveney, and Lauren K. Wright.(2000). 'Experiential Learning Exercises in Service Marketing Courses.' Journal of Marketing Education, 22(1):35-44.

Gwynne, M. (2003). Applied Anthropology: A Career-Oriented Approach. Boston: Allyn \& Bacon.

Jordan, A. (2003). Business Anthropology. Prospect Heights, IL: Waveland Press.

-. (2010). 'The Importance of Business Anthropology: Its Unique Contributions.' International of Journal of Business Anthropology, 1(1):15-25.

Orr,J. (1995). Through the Looking Glass: The curious Relations of Practice, Narratives, Memory and Organization. Palo Alto, CA: Systems and Practices Laboratory, Xerox Palo Alto Centre Report.

Reice, H. (1993). Occupational Subcultures in the Workplace. Ithaca, NY.

Schwartz, P.(1991). Art of the Long View. New York, NY.

Sigamani. P and Malhotra. S .(2013). 'Challenges and Emerging Trends in Human Resource Management.' International Journal of Business Anthropology, 4(2):85-100.

Tian RG .(2005). From Theory to Practice: Anthropology in business education. High Plains Applied Anthropologist, 25(1): 13-22.

Tian R and Lillis, Michael .(2009). 'Cross-Cultural Communication and Emotional Intelligence.' Marketing Intelligence \& Planning, 3-27. 
Tian RG and Walle A. (2009). 'Anthropology and Business Education: Practitioner applications for a qualitative method.' International Journal of Management Education, 2-7.

Tian RG, Van Marrewjik AH, Lillis M. (2013). General Business Anthropology. $2^{\text {nd }}$ Edition. Miami, FL: North American Business Press.

Tian R, Trotter D, Zhang L and Shao H.(2014). 'The Importance of Foodservice in Higher Education: A Business Anthropological Case Study in China.' Anthropologist, 1-18.

Ybema S, Yanow D, Wels H, Kamsteeg F. (2009). Organizational Ethnography. Studying the Complexities of Everyday Life. London: Sage. 
